\title{
Hospital training for general practice: views of trainees in the North Western region
}

\author{
Hugh Reeve, Ann Bowman
}

\begin{abstract}
Vocational trainees in the North Western region who were in their general practice year completed a questionnaire concerning the hospital component of their training. Replies were received from 125 trainees, providing information about 451 hospital posts. In a total of 372 posts $(85 \%)$ less than two hours of formal teaching a week was provided. Trainees stated that they received no informal teaching in nearly one third of posts. The orientation of teaching towards general practice was reported as greatest in the posts that were not part of a vocational training scheme. Study leave was applied for by doctors in only $163(37 \%)$ posts, usually to prepare for or to sit an examination.

There seem to be serious educational deficiencies in hospital posts that are used to train both general practitioners and other specialists. Improvements in both the quantity and quality of in service teaching are therefore needed urgently.
\end{abstract}

\section{Introduction}

Vocational training for general practice has developed rapidly over the past two decades. Since 1982 it has been required by law that two of the three years of training are spent in educationally approved posts in hospital or community medicine. ${ }^{12}$ The selection of these posts is the responsibility of regional committees and is carried out according to guidelines issued by the Joint Committee on Postgraduate Training for General Practice. ${ }^{3}$

Most of the published results of research on vocational training concentrates on the year spent in general practice. $^{4-7}$ Although little information is available regarding the hospital component of training, there has been concern recently about the effect of long working hours on both the performance and emotional stability of junior hospital doctors in general..$^{8-10}$

In 1986 the trainee subcommittee of the North West England Faculty of the Royal College of General Practitioners was formed. The subcommittee decided to investigate the state of hospital training for general practice in the North Western region, with particular reference to its educational content. Manchester, Rusholme Health Centre, Manchester M14 5NP

Hugh Reeve, MRCGP, lecturer in general practice

The Health Centre, Longridge, Preston PR3 3RQ

Ann Bowman, MRCGP, general practitioner

Correspondence to: Dr Reeve.

BrMed f 1989;298:1432-4 Method and results

Vocational trainees undergoing their attachment year in general practice were asked by their course organisers to complete a confidential questionnaire tion jobs up to a maximum of six. In particular information regarding the availability of study leave and the quantity and quality of teaching and its relevance to general practice was sought. Nonrespondents were accounted for by trainees who were absent from their day release course when the question- naires were completed. The questionnaires were analysed and the results subjected to suitable statistical tests.

Of a possible 160 trainees, 125 replied, giving a response rate of $78 \%$, which compares well with similar studies. ${ }^{56}$ Forty four (35\%) were on a formal vocational training scheme in the North Western region, and 81 $(65 \%)$ were on an informal self constructed scheme of training. The last group had held hospital posts both within and outside the North Western region.

Information was collected for a total of 451 hospital jobs; $159(35 \%)$ were part of formal schemes within the North Western region and $292(65 \%)$ part of self constructed schemes of training. In the last group 176 jobs were in the north west, and 116 were elsewhere in the United Kingdom. Some trainees in the self constructed group provided information for several posts in the same specialty. At this point in their training 30 trainees (37\%) on a self constructed scheme had completed fewer than four hospital posts compared with only eight (18\%) trainees on a formal scheme. The average number of posts completed for both groups, however, was the same, 3.6. Table I shows the range of hospital posts previously held by trainees. Those on a formal scheme were significantly more likely to have held a post in obstetrics and gynaecology or paediatrics than those who were on a self constructed scheme.

TABLE I-Range of hospital experience of trainees comparing experience gained on formal vocational training schemes and on self constructed schemes. Figures are numbers (percentages) of trainees

\begin{tabular}{llcc}
\hline & $\begin{array}{c}\text { Vocational } \\
\text { training } \\
\text { scheme } \\
(\mathbf{n}=44)\end{array}$ & $\begin{array}{c}\text { Self } \\
\text { constructed } \\
\text { scheme } \\
(\mathbf{n}=81)\end{array}$ & $\begin{array}{c}\text { All trainees } \\
(\mathbf{n}=125)\end{array}$ \\
\hline Specialty & $39(89)^{\star \star}$ & $51(63)^{\star \star}$ & $90(72)$ \\
\hline Obstetrics and gynaecology & $21(48)$ & $53(65)$ & $74(59)$ \\
Accident and emergency & $32(73)^{\star \star}$ & $35(43)^{\star \star}$ & $67(54)$ \\
Paediatrics & $25(57)$ & $38(47)$ & $63(50)$ \\
Geriatrics & $24(55)$ & $31(38)$ & $55(44)$ \\
Medicine & $17(39)$ & $28(35)$ & $45(36)$ \\
Psychiatry & $1(2)^{\star \star}$ & $31(38)^{\star \star}$ & $32(26)$ \\
Others & & &
\end{tabular}

^Experience included if trainee had spent at least six months in that specialty.

$\star \star$ Difference between the two schemes significant, $p<0.01$ ( $\chi^{2}$ test).

\section{TEACHING}

Table II shows the number of hours of formal and giving details of their most recent hospital postregistra- 
less likely to be reported as orientated towards general practice than teaching in posts in a self constructed scheme.

\section{STUDY LEAVE}

Table IV shows the reported outcome of applications for study leave. A significantly higher proportion of trainees applied for and obtained study leave while in posts elsewhere in the UK compared with those in posts in the North Western region. Study leave was used for many purposes. On 102 occasions it was used to sit an examination, and in 49 cases to attend a course, most commonly in family planning. On three occasions trainees in posts outside the North Western region obtained leave for private study. Six trainees, all of whom were on a formal scheme, spent time in general

TABLE II - Hours of formal and informal teaching reported comparing posts on formal vocational training schemes and self constructed schemes. Figures are numbers (percentages) of posts

\begin{tabular}{|c|c|c|c|c|}
\hline \multirow[b]{2}{*}{ Hours per week } & \multirow{2}{*}{$\begin{array}{c}\text { Vocational } \\
\text { training } \\
\text { scheme: } \\
\text { North west } \\
(n=159) \\
\end{array}$} & \multicolumn{2}{|c|}{ Self constructed scheme } & \multirow[b]{2}{*}{$\begin{array}{l}\text { All posts } \\
(n=436)^{\star}\end{array}$} \\
\hline & & $\begin{array}{l}\text { North west } \\
(n=167)\end{array}$ & $\begin{array}{c}\text { Elsewhere } \\
(n=110)\end{array}$ & \\
\hline \multicolumn{5}{|c|}{ Formal teachingt: } \\
\hline 0 & $71(45)$ & $66(40)$ & $26(24)$ & $163(37)$ \\
\hline Up to 2 & $77(48)$ & $77(46)$ & $55(50)$ & $209(48)$ \\
\hline 2 or over & $11(7)$ & $24(14)$ & $29(26)$ & $64(15)$ \\
\hline \multicolumn{5}{|c|}{ Informal teaching:: } \\
\hline 0 & $48(30)$ & $52(31)$ & $23(21)$ & $123(28)$ \\
\hline Up to 2 & $79(50)$ & $71(43)$ & $58(53)$ & $208(48)$ \\
\hline 2 or over & $32(20)$ & $44(26)$ & $29(26)$ & $105(24)$ \\
\hline
\end{tabular}

No response given for 15 posts.

†Formal teaching $=$ clinical meetings, organised tutorials, or seminars.

Difference between North Western region (vocational training scheme+

self constructed scheme) and elsewhere significant, $p<0.01\left(\chi^{2}\right)$.

Difference between vocational training scheme and self constructed scheme (North Western + elsewhere) significant, $p<0.001\left(\chi^{2}\right)$.

Difference between vocational training scheme (North Western) and self constructed scheme (North Western) not significant.

$\neq$ Informal teaching=discussions on ward rounds, in clinics, over coffee, etc.

No significant differences between the groups of posts.

TABLE III - Reported orientation of teaching towards general practice comparing posts on formal vocational training schemes and self constructed schemes. Figures are numbers (percentages) of posts

\begin{tabular}{lcccc}
\hline & $\begin{array}{c}\text { Vocational } \\
\text { training }\end{array}$ & \multicolumn{2}{l}{ Self constructed scheme } & \\
$\begin{array}{l}\text { Orientation of } \\
\text { teaching towards }\end{array}$ & $\begin{array}{c}\text { North west } \\
(\mathbf{n}=132)\end{array}$ & $\begin{array}{c}\text { North west } \\
(\mathbf{n}=148)\end{array}$ & $\begin{array}{c}\text { Elsewhere } \\
(\mathbf{n}=104)\end{array}$ & $\begin{array}{c}\text { All posts } \\
(\mathbf{n}=384)^{\star}\end{array}$ \\
\hline general practice & $40(30)$ & $32(22)$ & $14(13)$ & $86(22)$ \\
\hline 1 Not at all & $39(29)$ & $40(27)$ & $25(24)$ & $104(27)$ \\
2 & $26(20)$ & $43(29)$ & $32(31)$ & $101(26)$ \\
3 & $26(20)$ & $24(16)$ & $21(20)$ & $71(18)$ \\
4 & $1(1)$ & $9(6)$ & $12(12)$ & $22(6)$ \\
5 Completely & 2.31 & 2.58 & 2.92 & 2.58 \\
Mean score & & & &
\end{tabular}

$\star$ No response given for 67 posts.

Difference between vocational training scheme and self constructed Difference between vocational trainis

Difference betwe signifart, Difference between vocational training scheme (North W.

Difference between self constructed scheme (North Western) and self constructed scheme (elsewhere) significant, $\mathrm{p}<0 \cdot 05$.

(Statistical test-difference between means.)

TABLE IV-Reported outcome of applications for study leave com paring posts on formal vocational training schemes and self constructed schemes. Figures are numbers (percentages) of posts

\begin{tabular}{lcccc}
\hline & $\begin{array}{c}\text { Vocational } \\
\text { training } \\
\text { scheme: }\end{array}$ & \multicolumn{2}{c}{ Self constructed scheme } & \\
\cline { 3 - 4 } $\begin{array}{l}\text { Reported outcome } \\
\text { of application }\end{array}$ & $\begin{array}{c}\text { North west } \\
(\mathrm{n}=159)\end{array}$ & $\begin{array}{c}\text { North west } \\
(\mathrm{n}=168)\end{array}$ & $\begin{array}{c}\text { Elsewhere } \\
(\mathrm{n}=114)\end{array}$ & $\begin{array}{c}\text { All posts } \\
(\mathrm{n}=441)^{\star}\end{array}$ \\
\hline Successful & $43(27)$ & $45(26)$ & $49(43)$ & $137(31)$ \\
Unsuccessful & $12(8)$ & $8(5)$ & $6(5)$ & $26(6)$ \\
Did not apply & $104(65)$ & $115(68)$ & $59(52)$ & $278(63)$ \\
\hline
\end{tabular}

se given for 10 posts.

Difference between both schemes in North Western region (vocational training scheme + self constructed scheme) and elsewhere significant, $\mathrm{p}<0.01\left(\chi^{2}\right)$.

Difference between vocational training scheme (North Western) and self constructed scheme (North Western) not significant. practice, but there were no reports of leave being granted to gain experience in other specialties, such as ophthalmology and dermatology.

Leave was often refused as the topic for study was not related to the current post and also because it was not being used to attend a course or sit an examination. One "general practice" trainee was told that he was employed partly to cover the study leave of the "specialist" trainees. In 279 posts $(63 \%)$ trainees did not apply for study leave. In 204 posts they saw no need for it, usually because they were not preparing for or sitting an exam. In a further 52 posts they thought that the workload was too high to reasonably expect their colleagues to cover for them. For this reason informal agreements sometimes existed whereby none of the junior staff applied for study leave. Several trainees commented that it was difficult to obtain their full entitlement of annual holiday leave let alone study leave.

\section{Discussion}

The findings in many ways raise more questions than they answer. We recognise that the results are based on doctors' subjective recollections of posts, which in some cases had been completed several years before the study. But we think that many serious educational deficiencies have been highlighted in hospital posts that are used for training not only future general practitioners but also other specialists.

No formal teaching was apparently received in 163 (37\%) posts, while in $209(48 \%)$ posts up to two hours a week only was provided. Recent studies from the Office of Manpower Economics, ${ }^{11}$ which indicate that formal educational activities occupy only 1.86 hours of a senior house officer's average working week, support these findings. Formal teaching was less likely to be received in posts in the North Western region than in the posts elsewhere in the UK. Whether this is representative for other regions is difficult to say. Equal educational opportunities may have existed in both groups of posts. The disparate uptake of these opportunites may be due to a higher service commitment in the posts in the north west, but it is also possible that we are looking at two differently motivated groups of trainees.

The importance of informal teaching by example and discussion has recently been emphasised. ${ }^{12} 13$ Trainees reported that in $123(28 \%)$ posts they received no informal teaching, and in a further $208(48 \%)$ it was less than two hours a week. By its nature informal teaching is often a covert activity unrecognised by both teacher and pupil alike. For this reason some caution must be expressed when interpreting these results.

Study leave is also recognised as an important aspect of basic specialist training. ${ }^{32}{ }^{13}$ It was applied for in only $163(37 \%)$ posts. This is disconcertingly low given that it applies to posts that have been approved for training. The existence of local agreements not to apply for study leave is of particular concern. Some evidence was received that "general practice" trainees were discriminated against in favour of the "specialist" trainees. Few trainees were encouraged to see it as an opportunity to broaden their clinical experience, which is of real importance in general practice training. It seems that in some posts this approach was actively discouraged. It has recently been recommended that the numbers of senior house officers in certain specialties are increased to provide cover for study leave. ${ }^{13}$ If implemented this recommendation could lead to appreciable financial savings as the cost of an agency locum at this level is considerably greater than the cost of a substantive employee. ${ }^{14}$

Doctors who enter formal vocational training schemes are, quite reasonably, likely to have high 
expectations of them. Our results show that trainees on these schemes were more likely to complete a post in obstetrics and gynaecology or paediatrics, though little educational advantage seems to have been gained as they did not receive more teaching and had similar difficulties obtaining study leave as trainees on self constructed schemes. Surprisingly, they were also less likely to consider the teaching they did receive as being orientated towards general practice, although this may be because their expectations were higher. This is a sad state of affairs. Formal vocational training schemes were developed to provide an integrated training programme of hospital and general practice posts. It seems that in the North Western region they fall well short of this. Is this also true for the rest of the UK?

In two important recent reports ${ }^{12}{ }^{13}$ the general issue of basic specialist training has been explored. Among the recommendations are that trainees need to participate regularly in organised educational activities; that each trainee should have a named educational supervisor responsible for both teaching and providing unambiguous feedback; and that training opportunities should be available to consultants and senior registrars to help develop their skills as teachers. In many ways these recommendations mirror what has happened in the general practice component of vocational training over the past decade.

We would add three further suggestions which have particular relevance to the North Western region. Firstly, priority should be given to the task of agreeing educational objectives for the hospital period of vocational training. ${ }^{15} 16$ Secondly, protected study leave should be organised during this period to allow educational input that is directly orientated towards general practice. Finally, trainees on a formal scheme should spend some time at the beginning of the scheme in an approved training practice, thus enabling them to direct their learning more appropriately during subsequent hospital posts.
We are encouraged because since this study was undertaken noticeable progress has been made in the North Western region towards implementing some of these recommendations. It is our hope that the publication of this paper will be a catalyst for further discussion and change.

We thank the North West England Faculty of the Royal College of General Practitioners for providing administrative support and funds for this study. We also thank the Regional Adviser in General Practice, and local course organisers for their cooperation.

1 Gray DJP. The history of vocational training. In: Training for general practice. Plymouth: MacDonald and Evans, 1982:1-17.

2 National Health Services Act. Sections 31,32. London: HMSO, 1977.

3 Joint Committee on Postgraduate Training for General Practice. Selection of posts in hospital and community medicine for vocational training in general practice. London: JCPTGP, 1980.

4 Ronalds C, Douglas A, Gray DJP, Selley O, eds. Fourth national trainee conference. London: Royal College of General Practitioners, 1981. (Occasional Paper 18.

5 Huson A, Cole F. A survey of general practice training in the North West region. Trainee 1982;2:46-53.

6 Cyna AM, Przyslo FR. Are the recommendations being met in the general practice year of vocational training? Trainees' views in the West Midlands Region. BrMed J 1987;294:416-8.

7 Carne S, ed. What others do: is vocational training for general practice working? Modern Medicine 1986; June:59-60.

8 Firth-Cozens J. Emotional distress in junior house officers. $\mathrm{Br}$ Med $\mathrm{f}$ 1987;295:533-6.

9 Kiff RS, Sykes PA. Who undertakes the consultation in the outpatients department? BrMed F 1988;296:1511-2.

10 Orton DI, Gruzelier JH. Adverse changes in mood and cognitive performance of house officers after night duty. Br Med f 1989;298:21-3.

11 Review Body on Doctors' and Dentists' Remuneration. Seventeenth report. London: HMSO, 1987.

12 General Medical Council: Education Committee. Recommendations on the training of specialists. London: GMC, 1987.

13 Council for Postgraduate Medical Education in England and Wales. The problems of the senior house officer. London: CPME, 1987.

14 Styles WMCN. Swan song of the CPME in England and Wales. $f$ R Coll Gen Pract 1988;38:389-90.

15 Tait I. Agreed educational objectives for the hospital period of vocational training. Fournal of the Association of Course Organisers 1987;2:179-82.

16 Oxford Region Course Organisers and Regional Advisers Group. Priority objectives for general practice vocational training. London: Royal College of General Practitioners, 1985. (Occasional Paper 30.)

(Accepted 17 February 1989)

\section{Nottingham University Medical School, Nottingham NG7 2UH Leon Polnay, FRCP, senior lecturer in child health Mike Pringle, MD, senior lecturer, department of general practice}

Correspondence to: $\mathrm{Dr}$ Polnay.

\title{
General practitioner training in paediatrics in the Trent region
}

\author{
Leon Polnay, Mike Pringle
}

\begin{abstract}
A total of 259 postal questionnaires were sent to all final year vocational trainees and new principals in general practice in the Trent region to find out how much training in paediatrics they had had. Questionnaires were returned by 105 trainees and 139 principals $(244 ; 94 \%)$. Overall $72 \%(175)$ had taken up a hospital post in paediatrics during training, but among the 138 doctors who were on or had completed a three year vocational training scheme the proportion was slightly higher $(82 \% ; 115)(p=0.01)$. Among the 175 who had had a post in paediatrics 108 $(62 \%)$ had been given teaching sessions every week, and for half of these doctors the sessions lasted over one hour a week.

Seventy five $(54 \%)$ of the 139 principals reported that in their training in a general practice they had received no teaching about child health and a fifth said that they had not attended a clinic for children; $47(34 \%)$ had received no training on procedures for dealing with cases of child abuse. The doctors who had held posts as senior house officers in paediatrics were more likely to report that they had adequate skills in paediatrics than those who had not, but overall only $62(44 \%)$ reported that they could run a preschool child health surveillance programme.
\end{abstract}

Extra paediatric posts in hospital are needed, but in the mean time improvements can be made to the teaching content in hospital and in the general practice attachment and postgraduate training in paediatrics provided for all general practitioners.

\section{Introduction}

It has been suggested that general practitioners should be more widely concerned in child health surveillance. In 1976 the Court report recommended the development of a specialist general practitioner paediatrician. ${ }^{1}$ In 1982 the Royal College of General Practitioners encouraged general practitioners to take a greater role in child health. ${ }^{2}$ Most recently the government's white paper has sought to expand the role of general practitioners in community health.

Because of the recommendations in these reports the paediatric training that general practitioners now receive needs to be reviewed. Figures from the Royal College of General Practitioners show that of the first 3916 applicants who registered with the college after completing postgraduate training in general practice only $1645(42 \%)$ had included a hospital post in paediatrics in their training scheme. The relevance to general practice of training in paediatrics in hospital 